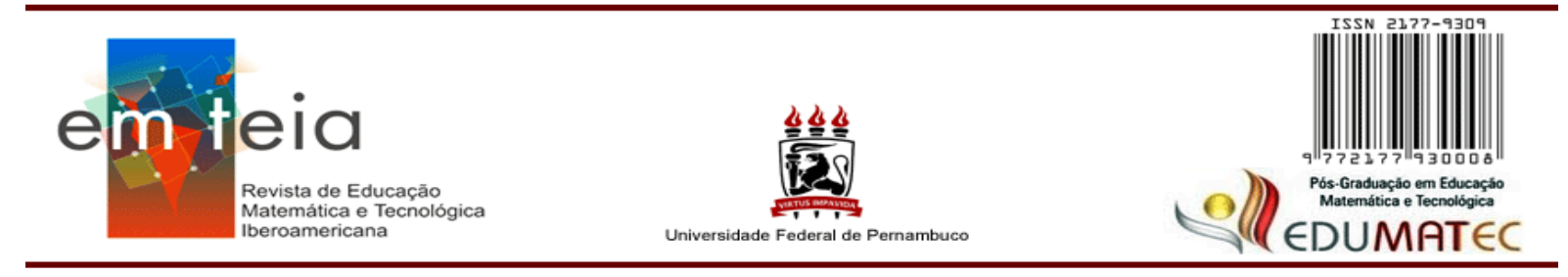

\title{
LINGUAGEM NATURAL E FORMAL NA SEMIOSFERA DA APRENDIZAGEM MATEMÁTICA: O CASO DA GEOMETRIA PARA A FORMAÇÃO DO PEDAGOGO
}

\author{
Méricles Thadeu Moretti \\ Doutor em Didática da Matemática/ULP/França \\ Programa de Pós-Graduação em Educação Científica e Tecnológica/UFSC \\ mthmoretti@gmail.com
}

Selma Felisbino Hillesheim Doutoranda em Educação Científica e Tecnológica/UFSC Secretaria Estadual da Educação do Estado de Santa Catarina/SED selmafh@yahoo.com.br

\begin{abstract}
Resumo
Estudos dão conta da fragilidade da formação matemática do professor pedagogo; em particular, essa fragilidade acentua-se ainda mais para o caso da geometria. Tal formação insuficiente influencia diretamente o processo de ensino e aprendizagem da geometria nos anos iniciais do ensino fundamental que é o momento inicial de preparação para o desenvolvimento do olhar, imprescindível à aprendizagem da geometria. Neste trabalho, pretendeu-se discutir, a partir da Semiosfera do Olhar que é um espaço que congrega diversos sistemas semióticos e que visa ao desenvolvimento do olhar em geometria, elementos indicativos de orientação à formação para professores pedagogos. Pensamos que os conjuntos integrados desses sistemas semióticos, voltados ao avanço da aprendizagem do olhar em geometria, podem fundamentar ações de ensino que visam à aprendizagem em geometria dos alunos dos anos iniciais do ensino fundamental.
\end{abstract}

Palavras-chave: Formação de professores. Semiosfera do Olhar. Apreensões em geometria.

\begin{abstract}
There are some studies that approach the weakness of the mathematical training of the educator; such fragility, however, is emphasized when it comes to geometry. Such insufficient training has a direct impact on the process of teaching and learning geometry in the early stages of elementary school, which is a crucial period for the preparation for the development of visualization, a crucial ability necessary for learning geometry. In this study, we intend to bring up to discussion, based on visual semiosphere, which is a sphere that gathers several semiotic systems and that aims at developing a proper visualization of geometry, guiding indicative elements towards the proper training for educators. We consider that the integrated sets of these semiotic systems related to the improvement of visual learning in geometry can underpin teaching actions related to learning geometry by students in early stages of elementary school.
\end{abstract}

Key Words: Educator training; Visual semiosphere; Learning geometry. 


\section{Introdução}

A formação matemática de professores pedagogos vem sendo percebida como uma questão fundamental nos sistemas educacionais. Existe uma preocupação com a formação dos futuros professores que irão lecionar nos anos iniciais no ensino fundamental, bem como com a formação continuada dos professores que já se encontram atuando nesse nível de ensino. Um exemplo dessa preocupação são os programas de formação continuada, oferecidos pelo Governo Federal. O Pacto Nacional pela Alfabetização na Idade Certa - PNAIC (BRASIL, 2014) é um programa de formação continuada para os professores do ciclo de alfabetização. A participação na formação do PNAIC no período de 2014 a 2017 nos fez perceber o quão frágil é a formação matemática do professor que atua nos anos iniciais do ensino fundamental. No ano de 2014, os temas abordados foram específicos da área da matemática. Podemos destacar, pela nossa experiência nessa formação, que os professores pedagogos carecem de fundamentos sólidos de matemática em todos os eixos do conhecimento matemático, a saber: Números e Operações; Pensamento Algébrico; Espaço e Forma/Geometria; Grandezas e Medidas e Tratamento da Informação/Estatística e Probabilidade. Dentre todos esses eixos, percebemos que o campo mais fragilizado é, sem dúvida, o da Geometria.

Nossa preocupação com a falta de orientação apresentada por professores frente aos conhecimentos geométricos, abordados durante a formação, fez-nos pensar em: qual programa de formação em geometria pode contribuir para a construção de conceitos e conhecimentos geométricos consistentes ao professor pedagogo que possa subsidiar o processo de ensino e aprendizagem da geometria nos anos iniciais do ensino fundamental? Como os conceitos geométricos podem ser abordados para propiciar a passagem dos olhares icônicos aos não icônicos?

Buscando respostas para esses questionamentos, propomo-nos, neste trabalho, a apresentar um indicativo de um programa de formação em geometria para professores pedagogos pautado na teoria dos registros de representação semiótica, no estudo das funções discursivas na aprendizagem matemática de Duval $(2004,2005,2012)$ e na ideia em Moretti (2013) da Semiosfera do Olhar.

Compreendemos que a Semiosfera do Olhar para a aprendizagem da geometria, de acordo com Moretti (2013), se refere à criação de um lugar favorável ao desenvolvimento de atividades que visam à aprendizagem da geometria, em que os olhares se interligam ao desenvolvimento de capacidades de visualização. Estabelecendo conexões entre esses dois 
campos teóricos é que surge a proposta de criarmos um ambiente que contribua à aprendizagem da geometria.

Independentemente da área de atuação do professor, é muito importante que ele detenha o conhecimento do conteúdo a ser ensinado. Mas isso, por si só, garantirá o sucesso do processo de ensino e aprendizagem? O que os professores precisam saber para poder ensinar? Como o corpo de saberes dos professores influencia no processo de aprendizagem dos seus alunos? Como o professor constrói o seu jeito de ensinar?

Muitos pesquisadores vêm estudando a base do conhecimento profissional para o ensino a partir de uma variedade de perspectivas teórico-metodológicas, dentre eles, podemos destacar Shulman (1986, 2005). O pesquisador foi um dos primeiros a destacar a importância do conhecimento específico dos conteúdos para o exercício da tarefa pedagógica. Segundo ele, o professor deve compreender a disciplina que vai ensinar com base em diferentes perspectivas e estabelecer relações entre vários tópicos do conteúdo disciplinar e entre sua disciplina e outras áreas do conhecimento (ALMEIDA; BIAJONE, 2007).

Shulman (2005, p. 11) explicita várias categorias de conhecimentos necessários à docência: a) conhecimento da matéria; b) conhecimento pedagógico geral; c) conhecimento curricular; d) conhecimento dos alunos e da aprendizagem; e) conhecimento dos contextos educativos; f) conhecimento didático do conteúdo; g) conhecimento dos objetivos.

Essas categorias, segundo o autor, podem ser agrupadas em: conhecimento do conteúdo específico, conhecimento pedagógico geral e conhecimento pedagógico do conteúdo. Isso significa, em suma, que o professor que vai ensinar geometria nos anos iniciais do ensino fundamental precisa ter um conhecimento filosófico, histórico e epistemológico sobre a geometria, para estar capacitado a ensinar os conceitos geométricos e as relações que se estabelecem entre eles, tendo como fundamentação a literatura acumulada no campo da geometria, bem como suas conexões com outras áreas do saber.

\section{A Formação matemática do professor pedagogo: o caso da geometria}

O ensino da geometria, quando comparado a outras áreas do conhecimento matemático, tem sido, para os professores, o mais desnorteador. De acordo com Lorenzato (1995), são inúmeras as causas para essa desorientação e, consequentemente, para a omissão do ensino da geometria nos anos iniciais. Porém, ele destaca duas razões que estão atuando forte e diretamente na sala de aula: 
A primeira é que muitos professores não detêm os conhecimentos geométricos necessários para realização de suas práticas pedagógicas. [...] uma pesquisa realizada com 255 professores de $1^{\mathrm{a}} /^{\mathrm{a}}$ séries com cerca de 10 anos de experiência de magistério: submetidos a 8 questões (propostas por alunos) referentes à Geometria plana euclidiana (conceitos de ângulo, paralelismo, perpendicularismo, círculo, perímetro, área e volume), foram obtidas 2040 respostas erradas, isto é, o máximo possível de erros. E mais: somente 8\% dos professores admitiram que tentavam ensinar Geometria aos alunos.[...] A segunda causa da omissão geométrica deve-se à exagerada importância que, entre nós, desempenha o livro didático, quer devido à má formação de nossos professores, quer devido à estafante jornada de trabalho a que estão submetidos (LORENZATO, 1995, p. 3-4).

Como consequência dessa situação, o professor que não conhece geometria também não conhece a importância que ela exerce como facilitadora dos processos mentais, valorizando o descobrir, o conjecturar e o experimentar. Nessa perspectiva, tudo indica que esses professores têm como dilema tentar ensinar geometria sem conhecê-la, um ensino às cegas sem embasamento teórico que sustente e conduza o processo de aprendizagem. Ou então, têm como segunda opção, não ensiná-la. Como alguém pode ensinar aquilo que não conhece? Essa pode ser mais uma das razões para o atual esquecimento e deficitário ensino da geometria nos anos iniciais.

É possível considerar que os futuros professores concluem cursos de formação sem conhecimentos de conteúdos matemáticos com os quais irão trabalhar, tanto no que concerne a conceitos quanto a procedimentos, como também da própria linguagem matemática que utilizarão em sua prática docente. Em outras palavras, parece haver uma concepção de que o professor polivalente não precisa 'saber Matemática' e que basta saber como ensiná-la (CURI, 2004, p. 76-77).

Curi (2004) aponta, nos resultados de suas pesquisas, o desconforto apresentado pelos professores polivalentes, chamados assim porque ministram todas as disciplinas neste nível de ensino, em relação ao ensino da geometria nos anos iniciais, bem como o desconhecimento dos professores a respeito das habilidades desenvolvidas por meio do ensino da geometria.

Em seus depoimentos, as alunas-professoras fizeram referências a "conhecimentos novos" para elas, dando grande ênfase aos conteúdos de geometria. Reiteradas vezes destacaram a pouca preparação que tiveram com relação à geometria e enfatizaram que a falta de conhecimentos dos conteúdos relativos a esse assunto as deixava inseguras para ensiná-los. Nas entrevistas, algumas alunas-professoras comentam que estudaram geometria apenas nas aulas de desenho geométrico. Além das falas, em alguns textos de escrita de memórias, elas revelaram que pouco estudaram de geometria, que o conhecimento que tinham não era suficiente para ensiná-la a seus alunos e que precisavam se apropriar deles (CURI, 2004, p. 139). 
A nossa experiência com a formação de professores no PNAIC, em 2014, mostra que a mesma angústia, apresentada pelos professores na pesquisa de Curi (2004), foi demonstrada também pelos nossos professores que participavam da formação. Ao iniciarmos os estudos relacionados ao campo espaço e forma/geometria, pedimos para que eles elaborassem um desenho que representasse a ideia que eles tinham a respeito de geometria. Nosso objetivo, nessa atividade, foi de fazer um mapeamento das percepções que os professores apresentavam sobre o conhecimento geométrico. As imagens, a seguir, são uma pequena amostra dos desenhos que surgiram nessa atividade. Entretanto, eles demonstram, de uma forma geral, as concepções que foram apresentadas a respeito desse tema.

Figura 1: Desenhos elaborados pelos professores
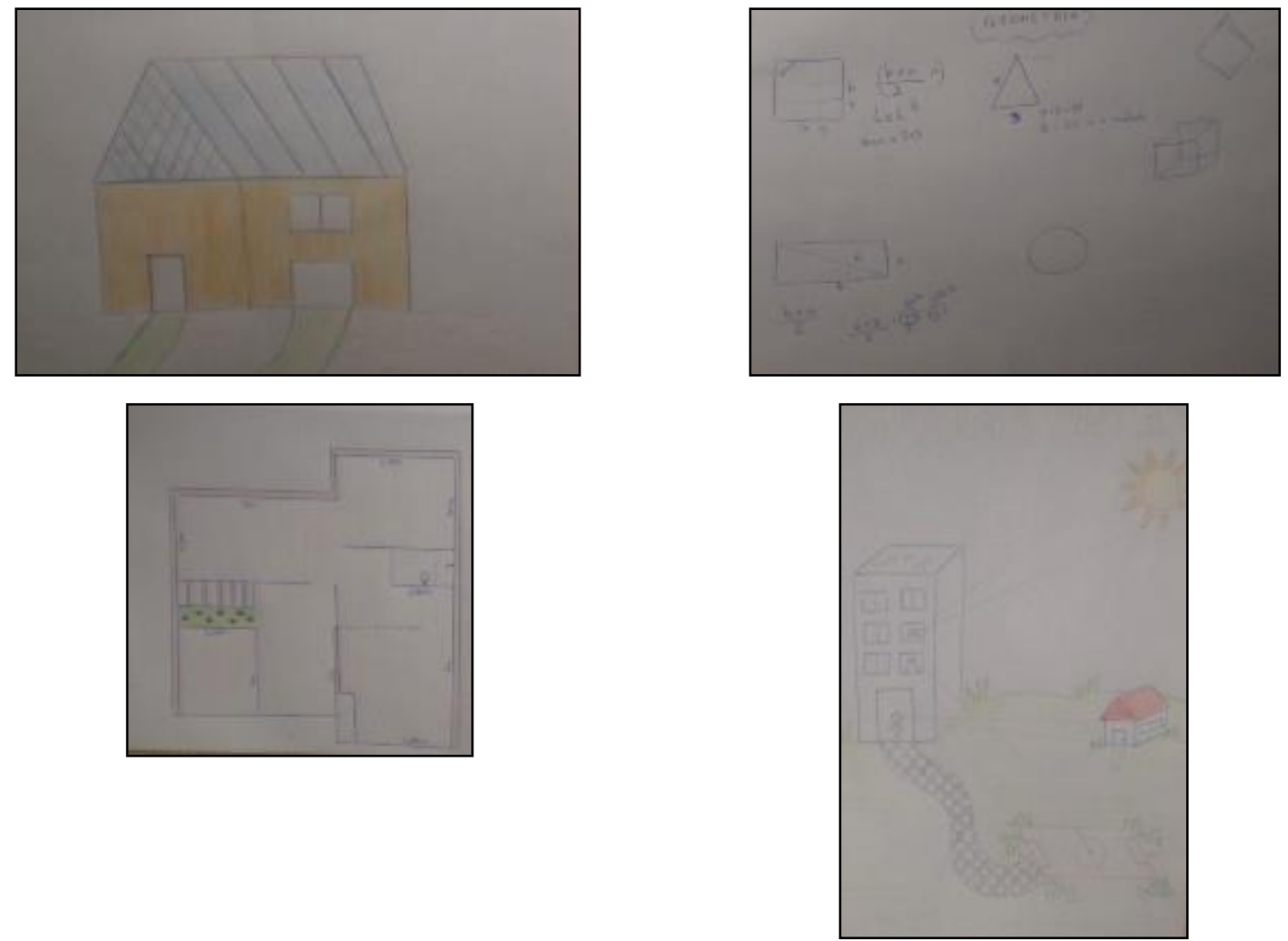

Fonte: arquivo pessoal dos autores.

Fazendo uma análise sucinta dos desenhos apresentados na Figura 1, é perceptível constatar, em todos os desenhos, a ideia de que a geometria restringe-se apenas à identificação das formas geométricas, bem como a sua aplicabilidade em situações reais. Em uma delas, há a identificação das formas e a aplicação de fórmulas para o cálculo de área.

É importante compreender como o professor se posiciona em relação às suas concepções do conhecimento matemático e, principalmente, do conhecimento geométrico e como ele enfrenta o processo de ensino da geometria na relação com o aluno e com o saber. Nossa 
posição, com relação à importância da formação geométrica dos professores pedagogos, segue a mesma direção apontada por Shulman (2005, p. 17):

O objetivo da formação de professores, não é doutrinar ou treinar professores para agir de maneira prescrita, mas educá-los para pensar bem sobre o que ensinar e como realizar o seu trabalho com competência. Para raciocinar bem se requer tanto um processo de reflexão sobre o que está sendo feito como uma adequada base de dados, princípios e experiências a partir do qual se pode pensar. Os professores precisam aprender a usar o conhecimento básico para fundamentar suas decisões e iniciativas. Consequentemente, a formação docente deve trabalhar com as conviçcões que norteiam as ações dos professores, com os princípios e as evidências que fundamentam as escolhas que fazem.

Podemos aferir, dessa maneira, que os professores precisam mais do que uma compreensão pessoal do conteúdo que ensinam. Eles necessitam possuir uma compreensão especializada da área do conhecimento que lhes permita criar condições para que seus alunos aprendam. Sendo assim, quando se aprende, por exemplo, geometria, para ensiná-la, o professor deve conhecê-la em profundidade, em todos os seus aspectos teóricos, filosóficos, históricos, epistemológicos e metodológicos. Isso porque o professor, ao ensinar elementos da geometria, necessita estar teoricamente fundamentado para abordar o conteúdo de diferentes modos, de atender as diferentes interpretações dos seus alunos. Nesse cenário, defrontamo-nos com um paradoxo: se os professores precisam usar o seu conhecimento de geometria para fundamentar as suas decisões e práticas pedagógicas, como os professores pedagogos poderão fundamentar teoricamente suas decisões, uma vez que essa base teórica se encontra fragilizada?

\section{As contribuições dos registros de representação semiótica e da Semiosfera do Olhar}

A teoria dos registros de representação semiótica nos traz importantes subsídios para discutirmos a formação em geometria do pedagogo. Duval (2005) nos faz pensar que o fato de ver uma figura em geometria é uma atividade cognitiva muito mais complexa do que o simples fato de reconhecimento daquilo que uma imagem mostra. $\mathrm{O}$ ato de ver envolve dois níveis de operação diferentes e independentes: o reconhecimento discriminativo de formas e a identificação dos objetos correspondendo às formas conhecidas.

A discriminação de formas é uma atividade importante que deve ser trabalhada pelos professores com as crianças dos anos iniciais: saber diferenciar um retângulo de um triângulo; um cubo de uma pirâmide etc. Entretanto, essa atividade, de acordo com Duval (2005), não tem nada de atividade geométrica, ela só parece ser geométrica, mas a mesma atividade de 
reconhecimento e iconicidade poderia ser feita, por exemplo, por meio do reconhecimento das formas das letras do alfabeto: “A visualização icônica repousa sobre uma semelhança entre a forma reconhecida num traçado e a forma característica do objeto a identificar" (DUVAL, 2005, p. 9). As formas são percebidas como sendo estáveis, pois são centradas sobre o contorno, impossibilitando, desse modo, qualquer modificação em outras formas parecidas ou diferentes.

Essas tendências pesadas da visualização icônica vão contra o desenvolvimento do que deve tornar o gesto reflexo para poder fazer da geometria: decompor toda forma, que se reconhece de emblema em um conjunto de traços ou em qualquer figura de ponto de partida, em uma configuração de outras unidades figurais do mesmo número de dimensões ou de um número inferior de dimensões (DUVAL, 2005, p. 10, grifos do autor).

A decomposição das formas exige duas maneiras diferentes para a sua execução. Em uma delas, a figura é produzida pelos instrumentos utilizados para a sua construção. Por exemplo, a atividade seguinte: “Construir um quadrado com 5 centímetros de lado". Essa atividade exige que a criança tenha conhecimento do que seja um quadrado, bem como suas propriedades, ângulos retos, lados com as medidas iguais, lados opostos paralelos, quatro vértices etc.

Entretanto, na outra maneira, a figura deve ser imaginada pelo observador que deve escolher o traço suplementar que permita a resolução do problema. Uma atividade que pode ilustrar essa outra forma de decomposição é perguntar para a criança, por exemplo, "quantas faces quadradas aparecem num cubo?’. Nessa situação a criança precisa ter conhecimento de que o quadrado e o cubo são formas com dimensões diferentes. Não será difícil encontrar crianças respondendo que o cubo é formado por um quadrado, pois muitas crianças ainda confundem o cubo com o quadrado. Assim, como confundem a pirâmide com o triângulo, a esfera com o círculo, o quadrado rotacionado com losango, dentre outras. Essa confusão não é uma situação encontrada apenas entre as crianças, ela pode ser percebida também entre os professores pedagogos, conforme observamos nas formações.

A maneira matemática de ver as figuras consiste em decompor qualquer forma discriminada, isto é, reconhecida como uma forma $\mathrm{nD} / 2 \mathrm{D}$, em unidades figurais de um número de dimensão inferior àquele dessa forma. Assim, a figura de um cubo ou de uma pirâmide (3D/2D) é decomposta em uma configuração de quadrados, triângulos, etc...(unidades figurais 2D/2D). E os polígonos são, por sua vez, decompostos em segmentos de lados (unidades figurais 1D/2D). E os lados, ou os segmentos, podem ser decompostos em "pontos" (0D/2D). Notemos que, com os pontos, nós saímos de toda a visualização (DUVAL, 2005, p. 18, grifos do autor). 
Essa maneira de ver as figuras contraria a ordem didática de introdução dos conhecimentos geométricos na escola. A organização da aquisição dos conhecimentos propostos nos manuais escolares privilegia a geometria euclidiana que segue a ordem crescente de dimensões: Pontos (0D) $\rightarrow$ segmento de reta (1D) $\rightarrow$ polígonos (2D) $\rightarrow$ Poliedros (3D):

Isso vai, então, em sentido contrário do trabalho longo e necessário de construção dimensional para entrar a compreensão dos conhecimentos geométricos. Privilegiar essa ordem retorna a fazer como se a construção dimensional fosse evidente, enquanto é contrária ao funcionamento normal e intuitivo da visualização (DUVAL, 2005, p. 49, grifos do autor).

Duval (2005) aponta que essa contradição cognitiva e paralizante entre a visualização e o discurso formal de exposição impede os funcionamentos cognitivos essenciais para construir o verdadeiro pensamento geométrico.

Visualização e discurso constituem dois tipos de funcionamento cognitivo que foram opostos frequentemente, tanto de um ponto de vista pedagógico, psicológico e matemático. No entanto, sua articulação é absolutamente decisiva para a aprendizagem da geometria. Pois, a atividade geométrica repousa sobre a sinergia cognitiva desses registros de representação (DUVAL, 2005, p. 50).

Em geometria, a articulação entre o ver e o dizer precisa ser mobilizada simultaneamente. É essa articulação que permite a apresentação das ideias e conceitos que foram utilizados ao longo da resolução do problema. É muito comum, na prática escolar, os alunos apagarem todos os registros das hipóteses anteriores ao resultado final, como se aquele processo não fizesse parte da resolução. $\mathrm{Na}$ atividade cognitiva requerida em geometria, é necessário que os tratamentos figurais e discursivos se efetuem de maneira interativa e ao mesmo tempo (DUVAL, 2004, p. 155).

De acordo com Duval (2012), os problemas geométricos apresentam uma especificidade em relação aos demais problemas matemáticos, pois o ensino da geometria passa pela condução de fazer o outro enxergar aquilo que eu vejo. E esse enxergar não se restringe ao simples fato do reconhecimento da imagem, mas, sim, de operar com essas formas. Duval (2012) apresenta três maneiras diferentes de ver as figuras segundo o seu papel: a apreensão perceptiva, a apreensão operatória e a apreensão discursiva.

A respeito da apreensão perceptiva de formas e interpretação figural de uma situação geométrica, Duval (2012) assinala que

Não importa qual figura desenhada no contexto de uma atividade matemática, ela é objeto de duas atitudes geralmente contrárias: uma imediata e 
automática, a apreensão perceptiva de formas; e outra controlada, que torna possível a aprendizagem, a interpretação discursiva dos elementos figurais. Estas duas atitudes encontram-se, geralmente, em conflito, porque a figura mostra objetos que se destacam independentemente do enunciado, assim como os objetos nomeados no enunciado das hipóteses não são necessariamente aqueles que aparecem espontaneamente (DUVAL, 2012, p. 120).

Vamos retomar uma situação muito comum no ensino fundamental, e até mesmo entre os professores pedagogos, ao ser apresentada uma caixinha de leite (bloco retangular ou paralelepípedo) e perguntado o nome desse objeto; as crianças prontamente respondem que se trata de um retângulo. Nesse caso, a apreensão perceptiva, que é automática e imediata, conduz a resposta da pergunta, uma vez que as faces desse paralelepípedo são retangulares.

Entretanto, é a apreensão discursiva que conduzirá ao sucesso da resposta, promovendo a interpretação dos elementos característicos do objeto (paralelepípedo), tais como, por exemplo, forma 3D, faces retangulares etc. [...] "Os alunos se apegam, na grande maioria, à apreensão perceptiva: estes não se dão conta de que uma figura deve ser olhada não mais do que através ou em função das propriedades, ou das condições formuladas como hipóteses" (DUVAL, 2012, p. 124).

A apreensão operatória diz respeito às modificações possíveis que uma figura pode sofrer, bem como as reorganizações perceptivas que estas mudanças operam. Duval (2012, p. 125) classifica essas modificações em: modificação mereológica, ótica e posicional. A modificação mereológica acontece da relação parte e todo. Ou seja, podemos dividir uma figura em subfiguras, incluí-la em outra figura de modo que se torne uma subfigura. Podemos ilustrar esse tipo de modificação por meio da situação: quantos quadrados são apresentados na figura?

Figura 2: Quadrado subdividido

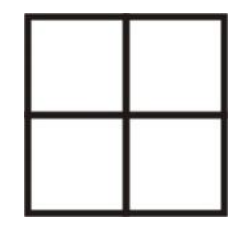

Fonte: os autores

Para ter sucesso na resposta dessa questão, a figura precisa ser vista como subfiguras que devem estar relacionadas com o todo. Essa questão, ao ser colocada num grupo de pedagogos, observamos que a maioria respondeu que a figura apresenta quatro quadrados. Isso porque eles não se atêm à sua decomposição em quatro quadrados menores que estão inseridos em um quadrado maior. 
Na modificação óptica, Duval (2012) diz que uma figura pode ser aumentada, diminuída ou deformada, em outras palavras, a figura pode ser transformada em outra chamada sua imagem. Essa modificação da figura permite que ela mantenha a sua forma inicial ou não. A modificação posicional se refere ao deslocamento ou rotação de uma figura em relação às referências do campo onde ela se destaca.

Cada uma dessas modificações é realizável graficamente ou mentalmente. Mas, diferentemente da construção geométrica, o modo escolhido para a modificação da figura é neutro: ele não muda a apreensão, nem mesmo a análise que pode ser feita. Em compensação, dependendo do tipo de modificação escolhida, podem surgir possibilidades de tratamento sem relação uns com os outros (DUVAL, 2012, p. 125, grifos do autor).

Com relação à apreensão discursiva de uma figura e demonstração, Duval (2012, p. 135) aponta que essa maneira de demonstração “[..] equivale a mergulhar, segundo as indicações de um enunciado, uma figura geométrica particular em uma rede semântica, que é, ao mesmo tempo, mais complexa e mais estável”. Isso porque a figura por si só não pode representar todas as suas características, ela precisa de uma indicação verbal para ancorar a figura como representação do objeto matemático. Sabe-se que as unidades figurais que podem identificar uma figura perceptivamente nem sempre estão em consonância com as indicações propostas no enunciado.

Isto implica subordinação da apreensão perceptiva à apreensão discursiva e, como consequência, uma restrição da apreensão perceptiva: uma figura geométrica não mostra a primeira vista a partir de seu traçado e de suas formas, mas a partir do que é dito. Esta subordinação da apreensão perceptiva à apreensão discursiva pode ser considerada como uma teorização da representação figural: a figura geométrica torna-se, de certa maneira, um fragmento do discurso teórico (DUVAL, 2012, p. 133).

Desse ponto, a apreensão discursiva pode ser negligenciada, quando existe a congruência semântica entre a operação matemática e o enunciado do problema. Entretanto, quando não há uma congruência semântica entre o enunciado e a operação operatória, a apreensão discursiva torna-se necessária. Nessa direção, “deve haver uma interação entre os tratamentos figurais que, por abdução, guiam a diligência heurística, e os tratamentos discursivos que, por dedução, constituem a diligência baseada nos objetos representados na figura" (DUVAL, 2004, p. 168).

Essas diferentes formas de apreensão do objeto matemático podem ser concebidas na perspectiva de Lotman (1996) por meio do conceito de semiosfera. Para esse autor, 
[...] não existem por si só de forma isolada sistemas precisos e funcionalmente unívocos que funcionem realmente. A separação deles está condicionada unicamente por uma necessidade heurística. Tomando por separado, nenhum deles tem, na realidade, capacidade de trabalho. Só funcionam estando submergidos em um continuum semiótico, completamente ocupado por formações semióticas de diversos tipos e que estão em diversos níveis de organização. A esse continuum, por analogia com o conceito de biosfera introduzido por V. I. Vernadski, é que chamamos de semiosfera (LOTMAN, 1996, p. 11).

A semiosfera compreende um espaço de encontro e de convivência de diversos sistemas semióticos diferentes. Esses sistemas semióticos distintos interagem por uma película fronteiriça que faz a tradução de uma linguagem a outra, limitando a semiotização do externo para o interno e sua conversão numa informação. Em outras palavras, a semiosfera se compõe como terrenos vizinhos separados por uma cerca, as cercas são como fronteiras que fazem a tradução das diferentes linguagens. Os indivíduos capazes de habitar dois terrenos vizinhos encontram-se em mais de um sistema semiótico. Nas periferias semióticas, encontramos as conexões existentes entre os diferentes sistemas sígnicos ${ }^{1}$. Para que essas conexões aconteçam, é preciso haver semelhanças e diferenças entre as suas linguagens. "A heterogeneidade é definida tanto pela sua diversidade de elementos quanto por suas diferentes funções" (LOTMAN, 1990, p. 125). Quanto mais heterogêneos são os sistemas integrados, mais promissoras são as possibilidades de ganho de informação (LOTMAN, 1990, p. 27).

Tudo se mistura e cria-se um significado no conjunto. Isso porque toda a parte de uma estrutura semiótica conserva todos os mecanismos para a reconstrução de todo o sistema. “A destruição dessa totalidade provoca um processo acelerado de 'lembrança' de reconstrução do todo semiótico por uma parte dele" (LOTMAN, 1996, p. 17). Trazendo essa afirmação para o estudo da geometria, por exemplo, a decomposição de um sólido geométrico gera uma lembrança que torna capaz a reconstrução do objeto novamente. Essa reconstrução da linguagem (sólido geométrico) sempre resulta na criação de uma nova linguagem, que não é a recriação da antiga, ao que parece do ponto de vista da autoconsciência e da cultura (LOTMAN, 1996).

A ideia da semiosfera baseia-se no

Conjunto de formações semióticas que precede (não heuristicamente, mas funcionalmente) a linguagem isolada particular e é uma condição da existência deste último. Sem semiosfera a linguagem não só não funciona, como

\footnotetext{
${ }^{1}$ Sistemas sígnicos são representações das diferentes formas de linguagens. Em matemática, podem ser pensados a partir das diferentes formas de representação de um objeto. Por exemplo, pode-se representar um objeto matemático utilizando-se a linguagem natural ou a sua representação geométrica.
} 
tampouco existe. As diferentes subestruturas da semiosfera estão vinculadas em uma interação e não podem funcionar sem apoiar-se umas nas outras (LOTMAN, 1996, p. 20)

A diversidade interna da semiosfera pressupõe a sua integridade; é ao mesmo tempo parte do todo e algo semelhante a ele. Os diferentes sistemas de representações semióticas permitem uma ampliação no modo de ver os objetos matemáticos, desenvolvem uma articulação com as suas diferentes formas de representação, trazendo uma riqueza intelectual da noção que se encontra sempre em formação.

O espaço de encontro e de convivências de sistemas semióticos diferentes cria uma fronteira que "aparta" os espaços internos e externos à semiosfera. Essa delimitação pode ser pensada, a partir dos trabalhos de Duval (2004), que seja a linguagem própria para o processo de ensino e aprendizagem da matemática. A língua natural é fundamental na comunicação e na criação de um espaço de construção didática em sala de aula. Entretanto, existem duas utilizações contrárias da língua natural como registro de representação semiótica nas situações de ensino.

Uma é a sua utilização comum e espontânea para fins de comunicação oral entre os alunos e entre os alunos e os professores em diferentes fases de uma sequência de atividades. A outra é a sua utilização matemática para fins de tratamento nas produções escritas para formular definições, para deduzir, a partir de propriedades dadas de outras propriedades utilizando teoremas, e também para descrever um problema aditivo, multiplicativo, de equacionamento ou de aplicação de uma propriedade geométrica (DUVAL, 2016, p. 19, grifos do autor).

Percebe-se, portanto, que, na aprendizagem matemática, a língua natural não desempenha apenas a função de comunicação que é exigida, outras funções discursivas são indispensáveis. Duval (2004, p. 88-89) considera uma língua quando um sistema semiótico seja capaz de cumprir todas as funções discursivas. A saber: i) Referencial: designar objetos; ii) Apofântica: dizer alguma coisa dos objetos que se designa sob a forma de uma proposição enunciada; iii) Expansão discursiva: religar a proposição enunciada a outras de forma coerente (descrição, inferência...); iv) Reflexividade: marcar um valor, ou modo, ou o estatuto acordado a uma expressão por aquele que a enuncia. De todas essas funções, a operação de designação da função referencial tem especial destaque.

[...] o que é essencial no domínio de uma língua natural não é o conhecimento do vocabulário, mas ter consciência de todas as operações que permitem articular as palavras em sintagmas nominais para designar objeto, proposições, ou para efetuar uma descrição coerente (DUVAL, 2016, p. 19). 
Esse domínio da linguagem natural que permite designar objetos, em matemática, está estreitamente relacionado à linguagem formal. A linguagem formal é entendida aquiz como a linguagem que permite que todas as funções discursivas sejam exercitadas nas aprendizagens matemáticas. Contudo, a linguagem natural e a linguagem formal (ou científica) não se opõem, elas se diferenciam nas operações postas em jogo para cumprir as mesmas funções discursivas, em que ora essas operações podem ser comuns e ora não (DUVAL, 2004, p. 93). Isso porque, na matemática, a linguagem natural é normalmente utilizada em sinergia cognitiva com outros registros de representação.

Sem essa relação, muitos problemas matemáticos se tornariam estranhamente incompreensíveis. Desse modo, quando nos referimos às aprendizagens matemáticas, é a linguagem formal que permite que as funções discursivas sejam consideradas. Tomemos, por exemplo, a situação "Decompor um retângulo em dois triângulos de mesma área”. Essa situação foi apresentada na linguagem natural, no entanto, para o procedimento de resolução são as funções discursivas que precisam ser tratadas.

É esta fronteira que fazemos referência, buscar nos elementos da linguagem natural aqueles elementos significativos da linguagem formal que podem ser transformados em outros elementos semióticos em um novo sistema de representação semiótica: o enunciado do problema pertence a um sistema semiótico discursivo que foi transformado em um sistema semiótico não discursivo próprio à álgebra para poder ser resolvido. Observemos que esta passagem exigiu o filtro da linguagem formal para que a transformação em um sistema de equação pudesse ser feita (MORETTI; BRANDT; SOUZA, 2017, p. 5).

Esse filtro precisa ser considerado no processo de ensino e aprendizagem da matemática. Ele permite considerar as formas diferentes de linguagem e a passagem assimétrica entre elas. Desse ponto, na semiosfera, as linguagens são semioticamente assimétricas, e é essa heterogeneidade de sistemas integrados que, segundo Lotman (1990, p. 27), possibilitam maior ganho de informação.

\section{Semiosfera do Olhar: um espaço para a aprendizagem da geometria}

Inspirado no conceito de semiosfera de Lotman (1996), Moretti (2013) apresenta uma nova perspectiva para o processo de ensino e aprendizagem da geometria nos anos iniciais do ensino fundamental, a saber, a Semiosfera do Olhar. 
A semiosfera do olhar é um lugar de criação para desenvolver atividades que visam à aprendizagem da geometria. [...] A ideia para a criação da semiosfera do olhar é incluir outros sistemas, permitir que diversos sistemas possam conviver com diferentes repercussões que não são percebidas quando do uso isolado de cada uma delas, os olhares se interligam à capacidade de coordenação visual motora (MORETTI, 2013, p. 296-298).

Moretti (2013) indica alguns exemplos de atividades que podem ser aplicadas nos anos iniciais do ensino fundamental que visam a promover a criação de uma Semiosfera do Olhar voltada para a coordenação visual motora e para a discriminação visual. Nessas atividades, é possível perceber que um mesmo conteúdo geométrico é capaz de permitir a criação de vários sistemas semióticos diferentes.

O autor sintetiza a ideia da Semiosfera do Olhar pelo esquema a seguir:

Figura 3: Nó de Borromeu que ilustra a relação entre os sistemas semióticos na Semiosfera do Olhar em

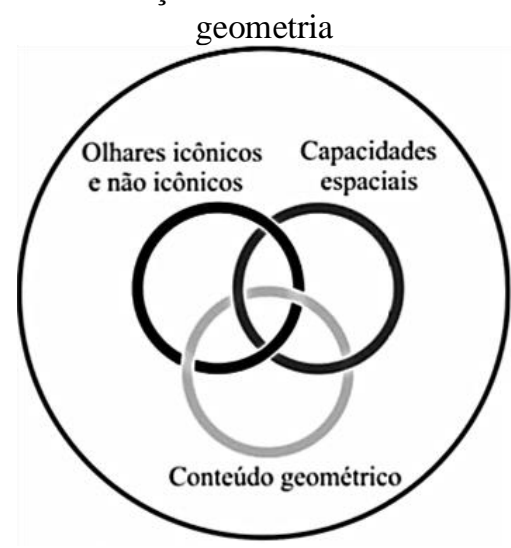

Fonte: Moretti (2013, p. 300)

No esquema, Moretti (2013) apresenta o nó de Borromeu, enfatizando que cada circunferência realiza um movimento tridimensional.

Os sistemas semióticos, imersos na linguagem natural, não se situam em um mesmo plano, no interior da circunferência maior, combinam-se para formar um novo espaço, um novo modo de olhar em geometria. A ideia da Semiosfera do Olhar permite que as capacidades espaciais se tornem dinâmicas, faz com que uma se interligue a outra; dinamiza também os olhares que podem passar, de forma indiferente, de um olhar icônico a outro, botanista ao agrimensor, e deles aos olhares não icônico (MORETTI, 2013, p. 300-301).

A respeito da passagem de um olhar icônico a outro e deles aos olhares não icônicos, Moretti (2013), a partir de Duval (2005), apresentou um esquema que ilustra a passagem desses olhares: 
Figura 4: As quatro maneiras de olhar uma figura geométrica

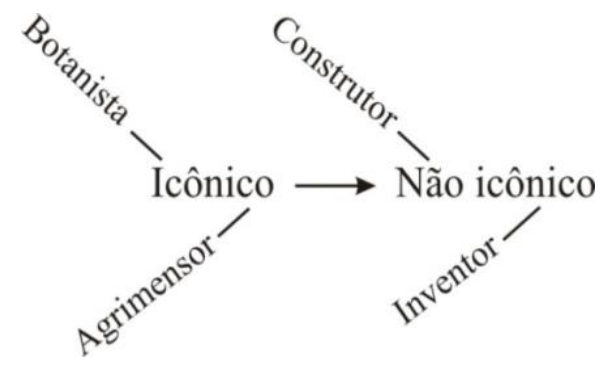

Fonte: Moretti (2013, p. 293).

Esse esquema possui uma orientação que vai do olhar do botanista a um olhar mais elaborado, o olhar do inventor. Apreender a olhar em geometria é aprender a fazer os olhares deste percurso. A passagem de uma maneira de ver para uma outra constitui uma alteração profunda de olhar, pois o funcionamento cognitivo envolvido em cada uma dessas maneiras de ver não é a mesma (DUVAL, 2005, p. 11).

Isso porque cada tipo de olhar apresenta uma especificidade diferente. O olhar botanista permite reconhecer o contorno de formas, é a entrada mais imediata e evidente, trata-se de um "olhar qualitativo". O olhar agrimensor faz medidas no terreno e consegue passar essas medidas para o plano do papel, mobilizando as propriedades geométricas para fins de medidas. "Ora, o fato de pôr em correspondência não tem nada de natural ou evidente, pois não há procedimento comum para medir as distâncias reais sobre o terreno e para medir as larguras de traçados de um desenho" (DUVAL, 2005, p. 9).

O olhar do construtor se forma no uso de instrumentos, régua não graduada e o compasso. $\mathrm{O}$ aluno pode tomar consciência que uma propriedade geométrica não é apenas uma característica perceptiva (DUVAL, 2005). Atualmente, alguns programas computacionais, como, por exemplo, o GeoGebra e o Cabrigéomètre podem substituir o uso desses instrumentos. O olhar inventor é aquele que, para resolver um problema, adiciona traços na figura dada, opera sobre a figura e a modifica para descobrir um procedimento de resolução. Esse tipo de olhar exige "[...] uma desconstrução visual das formas perceptivas elementares que se impõem a primeira vista, para poder obter a configuração ou a figura pedida" (DUVAL, 2005, p. 11).

Um exemplo que pode ilustrar essa passagem do olhar icônico ao não icônico é uma atividade de coordenação visual motora como o de resolver e fazer labirintos. 
Figura 5: modelo de labirinto

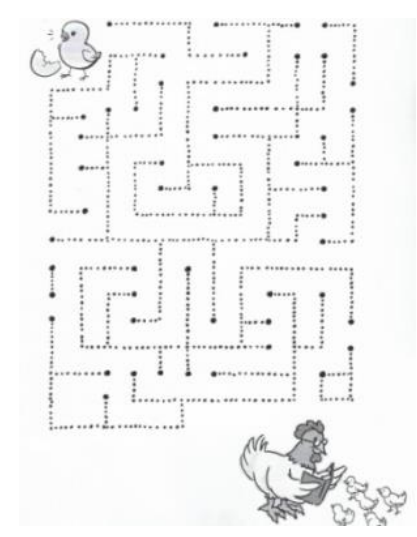

Fonte: imagem da internet

Essa atividade é geralmente feita a mão livre, podendo ou não ser feito o uso de régua. O uso simultâneo da régua e do lápis fortalece a coordenação e prepara o aluno para o desenvolvimento de habilidades requeridas no olhar do agrimensor e do construtor. Percebam que nesse tipo de atividade os movimentos do corpo precisam ser coordenados com outros movimentos.

Um outro tipo de atividade, pouco utilizada nos anos iniciais, diz respeito àquela que visa a desenvolver a discriminação visual. A discriminação visual é a capacidade para perceber e identificar diferenças e semelhanças entre objetos, formas, espaços etc. Na figura, a seguir, pode ser solicitado à criança que: 1) Pinte com a mesma cor as figuras que você acha que tem alguma coisa em comum; 2) Escolher algumas figuras e perguntar o que elas têm em comum; 3) Quais figuras possuem três lados?

Figura 6: Atividade de reconhecimento de características de figura

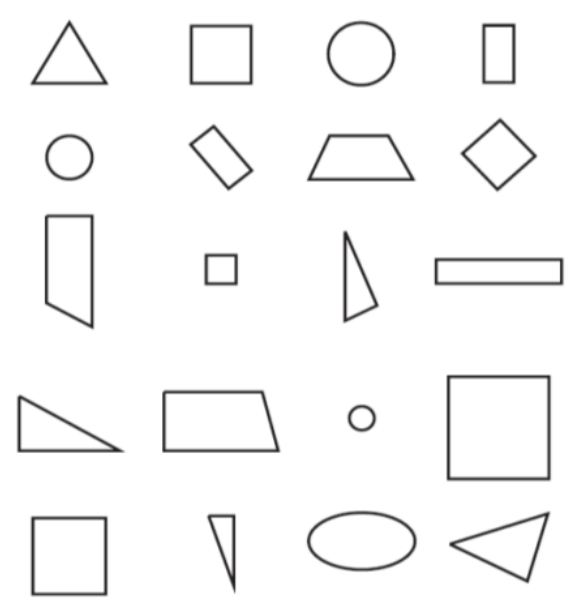

Fonte: Moretti (2013, p. 299). 
Nessa atividade, a passagem do olhar icônico para o olhar não icônico acontece quando a criança percebe as diferenças entre as formas, entre os tipos de triângulos, entre os tipos de quadriláteros etc. Quando ela percebe, também, as semelhanças como, por exemplo, de quadriláteros entre si, de formas circulares, de posição espacial, de que o tamanho da figura pode não alterar algumas propriedades (constância perceptual) etc.

Esses olhares caminham de um lado a outro conforme as apreensões em geometria são exigidas. No olhar do botanista, essencialmente, é a apreensão perceptiva que é exigida. $\mathrm{Na}$ outra ponta, todas as apreensões participam das atividades do olhar do inventor.

Passar de uma maneira de ver para uma outra constitui uma mudança profunda de olhar, que é tão frequentemente ignorado no ensino. Pois o funcionamento cognitivo implicado por cada uma de suas quatro maneiras de ver não é a mesma [...]. Mas já podemos enfatizar que cada maneira de ver induz um tipo particular e limitado de compreensão. O conhecimento desenvolvido não é o mesmo segundo o olhar onde um aluno se sente ser capaz ou incapaz de mobilizar, e isso na presença da mesma figura (DUVAL, 2005, p. 11).

Considerando esse contexto teórico, emerge uma indagação: qual programa de formação geométrica pode contribuir para a construção de conceitos e conhecimentos geométricos consistentes ao professor pedagogo que possa subsidiar o processo de ensino e aprendizagem da geometria nos anos iniciais do ensino fundamental?

\section{Considerações finais}

Nossas reflexões, pautadas nos resultados de pesquisas (CURI, 2004; FIORENTINI, 1995), apontaram que os conhecimentos geométricos que os professores pedagogos dispõem não são suficientes para subsidiar a sua prática pedagógica nos anos iniciais do ensino fundamental. Nossa experiência com a formação de professores no PNAIC ratificou esse resultado e mostrou o quão frágil é a formação matemática do professor pedagogo e que se agrava ainda mais no campo da geometria.

Shulman (1986) destaca a importância do conhecimento específico dos conteúdos para o exercício da atividade pedagógica. Desse modo, aferimos que o professor dos anos iniciais precisa ter uma base teórica consistente dos elementos da geometria para que ele possa abordar esse conhecimento adequadamente com as crianças, a fim de que elas construam os seus conhecimentos geométricos sem nenhum prejuízo em sua base conceitual.

Pensamos, então, que uma proposta de formação em geometria para os professores pedagogos pautada nos registros de representação semiótica e na Semiosfera do Olhar possa colaborar para uma fundamentação teórica capaz de subsidiar a sua prática pedagógica, no que 
tange ao processo de ensino e aprendizagem da geometria, nos anos iniciais do ensino fundamental.

Criar um espaço para a semiosfera da aprendizagem em matemática é proporcionar a sinergia entre diversos registros, ressaltando a importância da linguagem formal na aprendizagem da matemática. Considerar a linguagem formal no ensino da matemática tornase imprescindível, pois, por não termos acesso direto aos objetos matemáticos, tratamos apenas de suas representações.

Na aprendizagem matemática, tratamos de objetos ostensivos para chegar ao objeto não ostensivo. Podemos ter, para um mesmo objeto ostensivo, diversos registros. Esta possibilidade permite que se crie uma rede de semiosfera de aprendizagem da matemática e, com isso, pensar em uma organização dos conteúdos de aprendizagem em termos de semiosferas. Pensamos que um currículo que seja capaz de congregar as diversas semiosferas dos objetos de aprendizagem matemática possa ser um caminho promissor para a formação em geometria de professores pedagogos.

\section{Referências}

ALMEIDA, P. C. A.; BIAJONE, J. Saberes docentes e formação inicial de professores: implicações e desafios para as propostas de formação. Educação e Pesquisa. São Paulo, v. 33, n. 2, p. 281-295, maio/ago. 2007.

BRASIL. Pacto Nacional pela Alfabetização na Idade Certa. Cadernos de matemática. Brasília: MEC, SEB, 2014.

CURI, E. Formação de professores polivalentes: uma análise de conhecimentos para ensinar matemática e de crenças e atitudes que interferem na constituição desses conhecimentos. 2004. Tese (Doutorado) - Universidade de São Paulo (USP). São Paulo, 2004.

DUVAL, R. Semiosis y pensamiento humano: registros semióticos y aprendizajes intelectuales. Tradução de Myriam Vega Restrepo. Santiago de Cali: Universidad del Valle Instituto de Educación y Pedagogía, 2004.

Les conditions cognitives de l'apprentissage de la geometrie: développement de la visualisation, différenciation des raisonnements et coordination de leur fonctionnements. Annales de Didactique et des Sciences Cognitives. n. 10, p. 5-53, 2005.

Abordagem cognitiva de problemas de geometria em termos de congruência. Trad. Méricles T. Moretti. REVEMAT, v. 7, n. 1, UFSC/PPGECT, Florianópolis, 2012. 
Questões epistemológicas e cognitivas para pensar antes de começar uma aula de matemática. Trad. Méricles T. Moretti. REVEMAT, v. 11, n. 2. UFSC/PPGECT, Florianópolis, 2016.

FIORENTINI, D. Alguns modos de ver e conceber o ensino de matemática no Brasil. Revista Zetetiké, Campinas, n. 4, p. 1-37, 1995.

LORENZATO, S. Por que não ensinar geometria? Educação Matemática em Revista SBEM, Campinas, SP; UNICAMP, n. 4, p. 3-13, 1995.

LOTMAN, Y. M. The universe of the mind: a semiotic theory of culture. Trad. Ann Shukman. Londres: I. B. Tauris\&Co. LTD, 1990.

La semiosfera I. Trad. Desidério Navarro. Madrid: Ediciones Cátedra, 1996.

MORETTI, M. T. Semiosfera do olhar: um espaço possível para a aprendizagem da geometria. Revista Acta Scientiæ. v. 15, 2013.

; BRANDT. C. F.; SOUZA, R. N. S. Linguagem natural versus formal: diferenciação importante na construção de uma semiosfera da aprendizagem matemática. In: CAMPOS, M. A. T.; SILVA, M. R. Educação, movimentos sociais e políticas governamentais. Curitiba: Appris, 2017.

SHULMAN, L. S. Those who understand: knowledge growth in teaching. Educational Researcher, v. 15, n. 2, 1986, p. 4-14.

Conocimiento y enseñanza: fundamentos de la nueva reforma. Profesorado. Revista de Currículum y Formación Del Profesorado, v. 9, n. 2, p. 1-30, 2005. Disponível em: <http://www.ugr.es/ recfpro/Rev92.html>. Acesso em: 15 fev. 2017. 